\title{
STILAS: STEM Intercultural Leadership Ambassador Scholars in Biology, Marine Biology, and Engineering
}

\section{Dr. William J. Palm IV, Roger Williams University}

William Palm is Assistant Professor of Engineering at Roger Williams University, where he teaches Engineering Graphics and Design, Computer Applications for Engineering, Machine Design, Manufacturing and Assembly, Biomechanics, and Capstone Design. He previously worked as a product design engineer and consultant and taught at the U.S. Coast Guard Academy and Boston University. He holds a PhD in Mechanical Engineering from MIT and is licensed as a Professional Engineer in the Commonwealth of Massachusetts.

\section{Dr. Nicole Martino, Roger Williams University}

Dr. Nicole Martino is an assistant professor of engineering at Roger Williams University. Her area of expertise is civil engineering, more specifically structural engineering. Dr. Martino's current research areas include developing innovative tools to improve the learnability of topics in heavy analytical courses, and developing rapid, accurate and efficient bridge deck condition assessment models using ground penetrating radar.

\section{Dr. Benjamin David McPheron, Roger Williams University}

Benjamin D. McPheron is an Assistant Professor of Engineering at Roger Williams University. Dr. McPheron received his B.S.E.E. in Electrical Engineering at Ohio Northern University in 2010, and his $\mathrm{Ph} . D$. degree in Electrical Engineering from the Department of Electrical Engineering at The Pennsylvania State University in 2014. Dr. McPheron teaches Freshman Engineering and various courses in Electrical Engineering including Circuit Theory, Signals and Systems, Electromagnetic Theory, Digital Signal Processing, and Dynamic Modeling and Control. His research interests include Engineering Education, Control Systems, Robotics, and Signal Processing. 


\title{
STILAS: STEM Intercultural Leadership Ambassador Scholars in Biology, Marine Biology, and Engineering
}

\begin{abstract}
Women and minorities continue to be underrepresented in engineering, both nationally and at Roger Williams University. In 2012, women constituted just $12 \%$ of engineering graduates at the university, while minorities constituted just 4\%. In an effort to boost the enrollment, performance, and persistence of underrepresented students, the university applied for and received an NSF SSTEM grant to integrate engineering, biology, and marine biology students into an existing program supporting underrepresented students on campus. The combined program, known as STILAS, provides participants with a $\$ 10,000$ NSF scholarship, supplemented by the university, as well as dedicated tutoring and advising, and co-curricular activities such as field trips and guest speakers.

Midway through the final year of the 5-year grant, the results are impressive. Nine of the ten engineering student participants have either graduated in four years in engineering or are on track to do so (the tenth changed major to mathematics), compared to just $57 \%$ of women and $25 \%$ of underrepresented minorities entering the engineering program in 2011 or 2012. The STILAS engineering students' combined GPA is 3.60, compared to 3.30 for all women and 2.56 for all underrepresented minorities currently enrolled in engineering.

The program has benefited non-participants as well: persistence of women in engineering has increased from 54\% of those entering in 2011 to $92 \%$ of those entering in 2013 or after. Women made up 31\% of the graduating class of 2016, 2.5 times greater than the proportion in 2012. Persistence of underrepresented minorities has increased from $29 \%$ for those entering in 2011 to $50 \%$ for those entering in 2013 or after. Unfortunately, total enrollment of underrepresented minorities has not grown. The recruitment of underrepresented students has proven more challenging than their retention. Future work will focus on recruitment, including outreach to local high schools and the development of bridge and/or transfer programs.
\end{abstract}

\section{Introduction}

The National Science Foundation (NSF) Scholarships in Science, Technology, Engineering, and Mathematics (S-STEM) program funds scholarships and support systems for undergraduate STEM students demonstrating academic talent and financial need. ${ }^{1}$ In 2012, Roger Williams University received a $\$ 586,500 \mathrm{~S}-\mathrm{STEM}$ grant to support underrepresented students in biology, marine biology, and engineering. ${ }^{2}$ The resulting program is called STILAS: STEM Intercultural Leadership Ambassador Scholars. In the fifth and final year of the grant, this paper reports results to date and lessons learned. The paper focuses specifically on the engineering student participants, though results for the entire student cohort (engineering, biology, and marine biology) are presented where appropriate. 


\section{Institutional Profile}

Roger Williams University is a private, non-profit, regional comprehensive university with campuses in Bristol and Providence, Rhode Island. The university enrolls 4,100 traditional undergraduate students, as well as 800 continuing studies students and 700 graduate, law, and professional students. ${ }^{3} 54 \%$ of all undergraduate students are women, ${ }^{3}$ while $8-10 \%$ are underrepresented minorities (6\% Hispanic or Latino, 2\% Black or African American, 2\% two or more races). ${ }^{4}$ Undergraduate tuition and fees are $\$ 32,100$, total expenses including on-campus housing are $\$ 50,896$, and the average net price after financial aid is $\$ 35,755$. $^{4}$ The most recent 6year graduation rate was $64 \%$ (the 4 -year graduation rate for the same class was $56 \%$ ). ${ }^{4}$

Approximately $8 \%$ of undergraduate students major in engineering, while $9 \%$ major in biology or marine biology. Another $8 \%$ of students enroll in other STEM fields. The engineering program is housed in the School of Engineering, Computing, and Construction Management, and offers a B.S. in Engineering with specializations in Mechanical, Civil, Electrical, and Computer Engineering. Students may also define a custom specialization. In 2012, when the STILAS grant was awarded, women constituted $12 \%$ of the graduating engineering class, while underrepresented minority students constituted $4 \%$. As of this writing, approximately $18 \%$ of engineering students are women, and $8 \%$ are underrepresented minorities.

\section{Description of the STILAS Program}

The original intent of the STILAS program was to build on the university's existing Intercultural Leadership Ambassadors (ILA) program to support more STEM students. Started in 2007, the ILA program works to recruit and retain underrepresented and first-generation students. It has been quite successful, retaining $84 \%$ of its first-year students (better than the university-wide average of $83 \%$ ), but in 2011 only $5 \%$ of ILA participants were STEM majors. STILAS was to add STEMspecific recruiting and programming to attract new students to the university and perhaps convert some of the existing ILA students to STEM majors. The engineering and biology/marine biology programs were featured because they are the university's largest STEM departments. The goal was to support 15 students entering over the course of three years, starting in 2012-13.

The STILAS proposal was submitted to NSF in August 2011 but was not funded until July 2012, shortly before the start of the school year. Because of this late start, the initial STILAS participants were not actively recruited but rather were selected from those students who had already matriculated. Two first-year students were chosen, along with one sophomore and one junior to provide the opportunity for peer mentoring within the cohort. For the 2013-14 school year, eight new first-year students and one existing sophomore were selected for participation. The final group of six first-year students started in 2014-15. Because of attrition, three existing RWU students were added in 2015-16 and one more at the start of 2016-17. The numbers are summarized in Table 1. In total, the STILAS program has funded 23 different students, including 9 for their entire college career. 
Table 1: Number of STILAS Participants, by Year and Class

\begin{tabular}{ccccc|c}
\hline Academic Year & Freshmen & Sophomores & Juniors & Seniors & Total \\
\hline $2012-13$ & 2 & 1 & 1 & & 4 \\
$2013-14$ & 8 & $3^{\mathrm{a}}$ & 1 & 1 & 13 \\
$2014-15$ & 6 & $6^{\mathrm{b}}$ & $2^{\mathrm{c}}$ & 1 & 15 \\
$2015-16$ & & $6^{\mathrm{d}}$ & $5^{\mathrm{e}}$ & $2^{\mathrm{f}}$ & 13 \\
$2016-17$ & & & $7^{\mathrm{g}}$ & $4^{\mathrm{g}}$ & 11 \\
\hline
\end{tabular}

${ }^{a}$ An existing student was added as a sophomore after changing major into engineering.

${ }^{\mathrm{b}}$ One of the 2013-14 freshmen became financially ineligible. Another changed major to a non-STEM.

${ }^{c}$ One of the original freshmen was dismissed after three semesters for poor academic performance.

${ }^{\mathrm{d}}$ One of the 2014-15 freshmen transferred to another university to major in a STEM field not offered at RWU. An existing sophomore was added as a replacement.

${ }^{\mathrm{e}}$ One of the 2013-14 freshmen transferred to another university to major in a STEM field not offered at RWU. Another was dismissed after four semesters for poor academic performance. One existing junior was added as a replacement.

${ }^{\mathrm{f}}$ The student added as a sophomore in 2013-14 became financially ineligible. An existing senior was added as a replacement.

${ }^{\mathrm{g}}$ One of the 2013-14 freshmen was dismissed after five semesters for poor academic performance. An existing junior was added as a replacement.

As implemented, the STILAS program includes several key components. Foremost is the scholarship. Each STILAS participant receives $\$ 10,000$ from NSF and up to $\$ 16,000$ from the university, depending on need. Without these funds, most STILAS participants could not afford to attend RWU.

After the scholarship, the most significant aspect of the program is advising and mentoring. Each participant is assigned a full-time faculty advisor in their field, usually one of the grant PI's. The faculty meet with their STILAS advisees several times per semester. In addition to faculty advising, the participants receive ongoing support from staff and peer mentors. In the first two years the students met weekly with an ILA advisor, and as needed with peer mentors from the university's Center for Student Academic Success. Starting in the second year, staff oversight for STILAS shifted from the ILA program to the university Tutoring Center. The center's associate director and science coordinator maintain weekly contact with each of the participants for both academic and non-academic issues. The associate director also coordinates the collection of assessment data, including students' grades and their satisfaction with the STILAS program. She communicates with each student's instructors at the mid-term grade period and helps to resolve any issues the students have. Grant funds were used to hire five to seven peer tutors per year to work with the STILAS participants. While their official role is to provide tutoring, they also provide valuable peer mentoring. In addition to these STILAS-funded tutors, STILAS participants can also meet with other peer tutors paid for by general university funds.

The third major component of the program is a series of extracurricular activities organized by the PIs, the tutoring center staff, and the students themselves. The goal is to have at least two activities 
and one field trip per semester, some academic in nature, some professional, and others purely social. Examples include:

- A behind-the-scenes tour of the New England Aquarium, focusing on both the biological specimens and the technical systems needed to maintain them.

- A guided tour of the lab and manufacturing facilities at Depuy Synthes, a medical device manufacturer.

- A lab tour at Woods Hole Oceanographic Institute.

- A guest lecture and dinner discussion with a RWU Engineering alumna employed by Stryker Orthopaedics. She brought examples of the orthopaedic implants and surgical tools and discussed the biological and engineering issues surrounding them.

- A trip to a lecture by astrophysicist Neil DeGrasse Tyson.

- A resume workshop with the PIs, tutoring center staff, and others.

- A workshop on applying for NSF Research Experiences for Undergraduates.

Lastly, students are actively encouraged and mentored to secure summer internships and research experiences. The 23 student participants have already completed approximately 20 internships and summer research projects, most of them paid. Students interned with organizations such as the U.S. Naval Undersea Warfare Center, the Rhode Island Department of Transportation, and the Mystic Aquarium. Most of the research experiences were with RWU faculty, supported by a variety of grants. Several students have presented their work at academic conferences.

Program assessment is conducted by the PIs and focuses on: academic performance (GPA), retention in a STEM major, progress through the major (credits accumulated), graduation, postgraduate outcomes (STEM careers or graduate study), and impact on underrepresented student enrollments in STEM majors at RWU. Secondary metrics used for assessment include: usage of the tutoring center (number and length of visits), participation in summer research and internships, and student satisfaction. Students are expected to maintain a 3.0 GPA to remain eligible for the scholarship, though exceptions have been occasionally made in the event of extraordinary personal circumstances, with the approval of the NSF program officer. Four students did lose the scholarship after persistently poor academic performance. Two others lost financial eligibility due

to a change in personal circumstances. One of the two remained active in cohort activities, while the other chose not to.

\section{Results to Date}

For the sake of space, we present only the high-level results, including academic performance, retention, and graduation.

\section{Academic Performance}

In the first two years of the grant, the STILAS cohort's performance was worse than expected (though some individual students did very well). Three of the seven biology/marine biology students earned a GPA less than 2.1 in their freshman year and lost academic eligibility after two to four semesters. The engineers did better though two of the six did have one semester below 3.0. 
These poor results were due in part to the fact that the initial participants were selected from a small group of eligible students at the university, because the grant was awarded too late to recruit participants during the admissions process. In response to these poor initial results, the STILAS steering committee tightened the selection criteria to require at least a 3.0 high school GPA and a 550 math SAT score. That change, along with other program improvements, contributed to a dramatic improvement in performance starting in the third year. Figure 1 shows that the performance of the cohort has improved in almost every semester.

Currently, the cumulative GPA of the entire STILAS cohort and its graduates is 3.52, with all students above 3.0. The engineering participants and graduates have an average GPA of 3.60, significantly above the engineering program average of 2.99 (Student's $t$-test, $t(12)=5.87, p<$ 0.001 ). Figure 2 shows that both women and underrepresented minority STILAS engineers have outperformed their non-STILAS peers. Statistical analysis is ongoing to determine how much of this difference can be explained by incoming student characteristics, and how much can be attributed to the STILAS program.

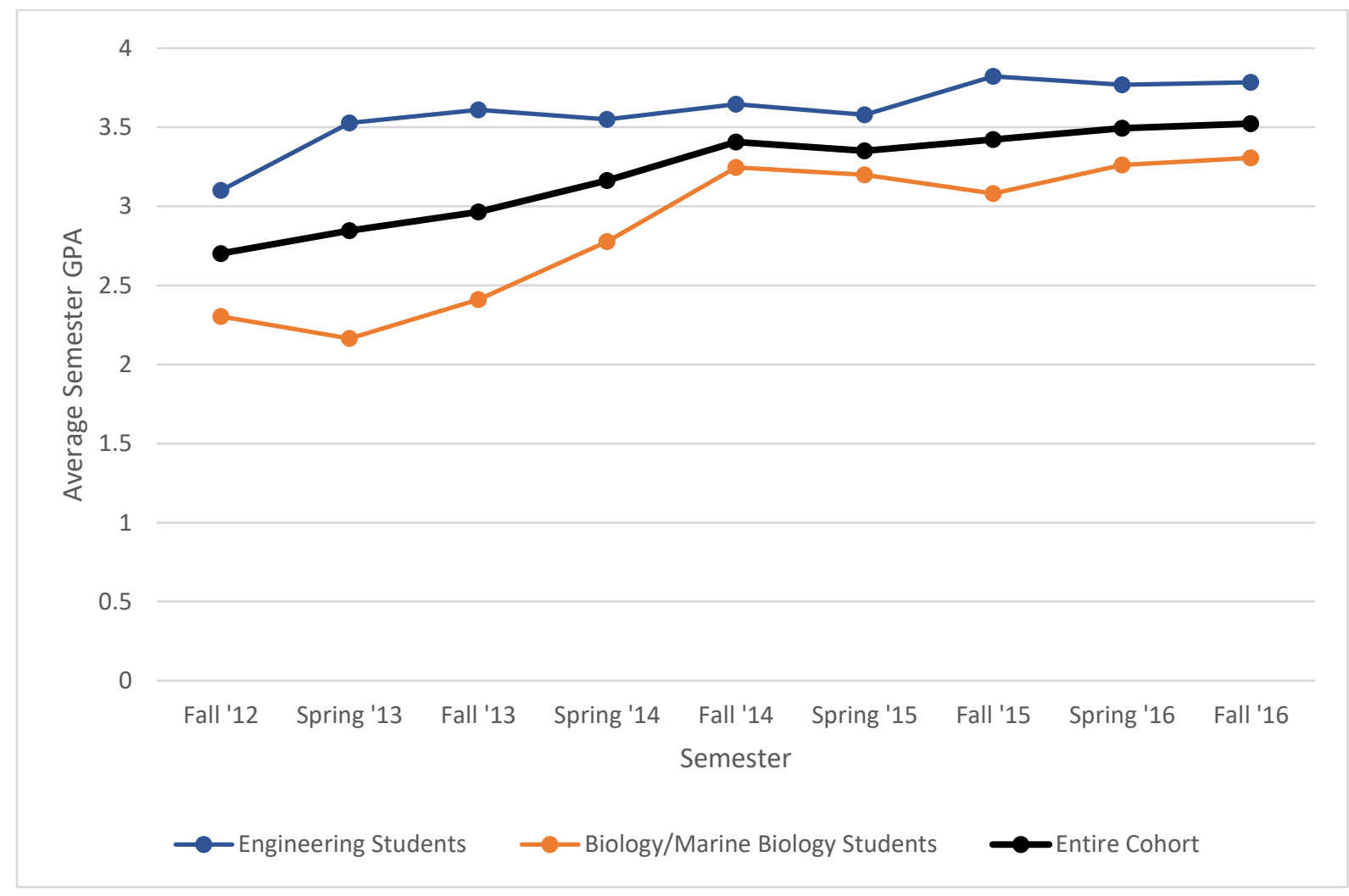

Figure 1: Academic performance of the STILAS cohort over time. 


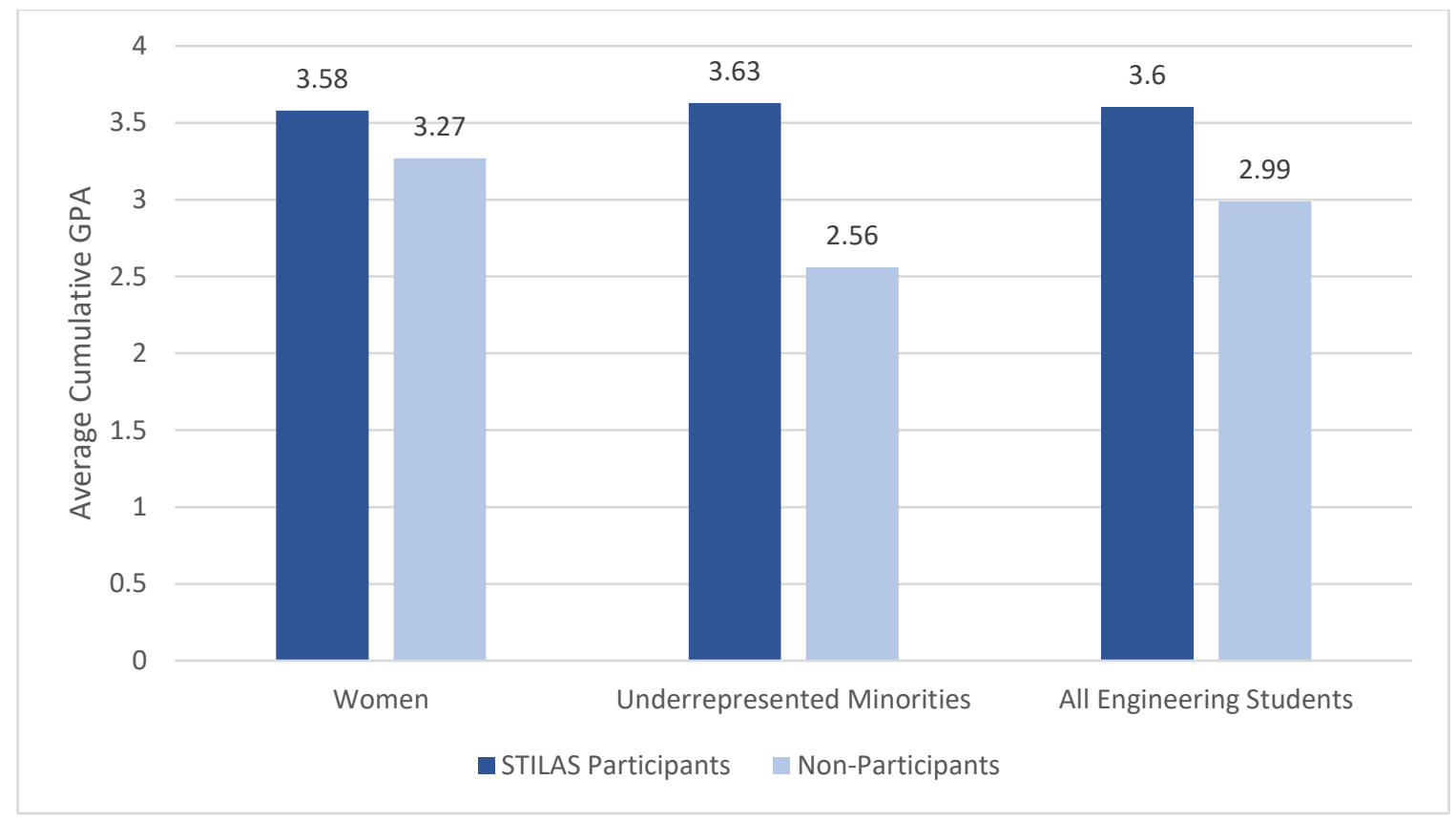

Figure 2: Academic performance of STILAS engineering participants compared to non-participants.

\section{Retention and Graduation}

Of the 23 students supported by the STILAS grant, 19 have either graduated in four years in a STEM major or are on track to do so. One of the four who did not is still enrolled at RWU in a non-STEM major. The other three left college altogether. Table 2 shows that all seven of the students who were entered STILAS after completing at least one year at the university were retained in STEM, whereas only 12 of the 16 starting as freshmen were. Table 3 shows that all 10 engineering participants were retained in STEM, while 9 of the 13 biology/marine biology students were. To put these results in context, only $57 \%$ of women and $25 \%$ of underrepresented minorities entering the engineering program in 2011 or 2012 graduated from RWU in four years in engineering.

Table 2: Student Retention in STEM, by Mode of Recruitment

\begin{tabular}{|c|c|c|c|c|c|}
\hline & \multicolumn{3}{|c|}{ Retained in STEM } & \multicolumn{2}{|c|}{ Not Retained in STEM } \\
\hline & $\begin{array}{l}\text { Graduated } \\
\text { from RWU in } \\
\text { STEM major }\end{array}$ & $\begin{array}{l}\text { On track to } \\
\text { graduate } \\
\text { from RWU in } \\
\text { STEM major }\end{array}$ & $\begin{array}{l}\text { Transferred to } \\
\text { another } \\
\text { university, } \\
\text { still STEM } \\
\text { major }\end{array}$ & $\begin{array}{l}\text { Remained at } \\
\text { RWU, } \\
\text { changed to } \\
\text { non-STEM } \\
\text { major }\end{array}$ & $\begin{array}{c}\text { Left } \\
\text { college } \\
\text { altogether }\end{array}$ \\
\hline $\begin{array}{l}\text { Recruited or selected } \\
\text { as a freshman }\end{array}$ & 1 & 9 & 2 & 1 & 3 \\
\hline $\begin{array}{l}\text { Selected from } \\
\text { existing RWU } \\
\text { students }\end{array}$ & 4 & 3 & & & \\
\hline Total & $5(21.7 \%)$ & $12(52.2 \%)$ & $2(8.7 \%)$ & $1(4.3 \%)$ & $3(13.0 \%)$ \\
\hline
\end{tabular}


Table 3: Student Retention in STEM, by Major

\begin{tabular}{lccc|cc}
\hline & \multicolumn{3}{c|}{ Retained in STEM } & \multicolumn{2}{c}{ Not Retained in STEM } \\
\cline { 2 - 6 } & $\begin{array}{c}\text { Graduated } \\
\text { from RWU in } \\
\text { STEM major }\end{array}$ & $\begin{array}{c}\text { On track to } \\
\text { graduate } \\
\text { from RWU in } \\
\text { STEM major }\end{array}$ & $\begin{array}{c}\text { Transferred to } \\
\text { another } \\
\text { university, } \\
\text { still STEM } \\
\text { major }\end{array}$ & $\begin{array}{c}\text { Remained at } \\
\text { RWU, } \\
\text { changed to } \\
\text { non-STEM } \\
\text { major }\end{array}$ & $\begin{array}{c}\text { Left } \\
\text { college } \\
\text { altogether }\end{array}$ \\
\hline Engineering & 4 & 6 & $2(8.7 \%)$ & $1(4.3 \%)$ & $3(13.0 \%)$ \\
Biology / Marine Bio & 1 & 6 & & & 1 \\
\hline Total & $5(21.7 \%)$ & $12(52.2 \%)$ & $2(20)$ & \\
\hline
\end{tabular}

\section{Post-Graduate Outcomes}

All five of the STILAS graduates to date (four engineers, one marine biologist) are presently employed in their field. The engineers are working for: the U.S. Department of Defense, a Big Three automaker, an Engineering News-Record (ENR) Top 200 contractor, and an ENR Top 400 design firm. The marine biologist accepted work with a major regional aquarium. Of the five students graduating in May 2017 (four engineers, one biologist), three have already accepted jobs in their fields, while another will be pursuing a master's degree at Boston University.

\section{Impact beyond the STILAS Cohort}

In addition to its impacts on the participants, the STILAS program has had spillover benefits to the academic departments and the university. Although we cannot prove causation, the persistence of women engineering students has increased dramatically during the course of the grant. As shown in Figure 3, only 54\% of women entering the engineering program in 2011 graduated in engineering. $66 \%$ of the entering class of 2012 did so. Since 2013, an astonishing $92 \%$ of women entering the engineering program are still majoring in engineering.

Figure 4 shows a similar, though less dramatic, story for underrepresented minorities. Only $25 \%$ of those entering in 2011 or 2012 graduated in engineering, whereas $50 \%$ of those entering since 2013 have persisted to date. Of the 50\% who have not persisted in engineering, half changed major to Construction Management. 


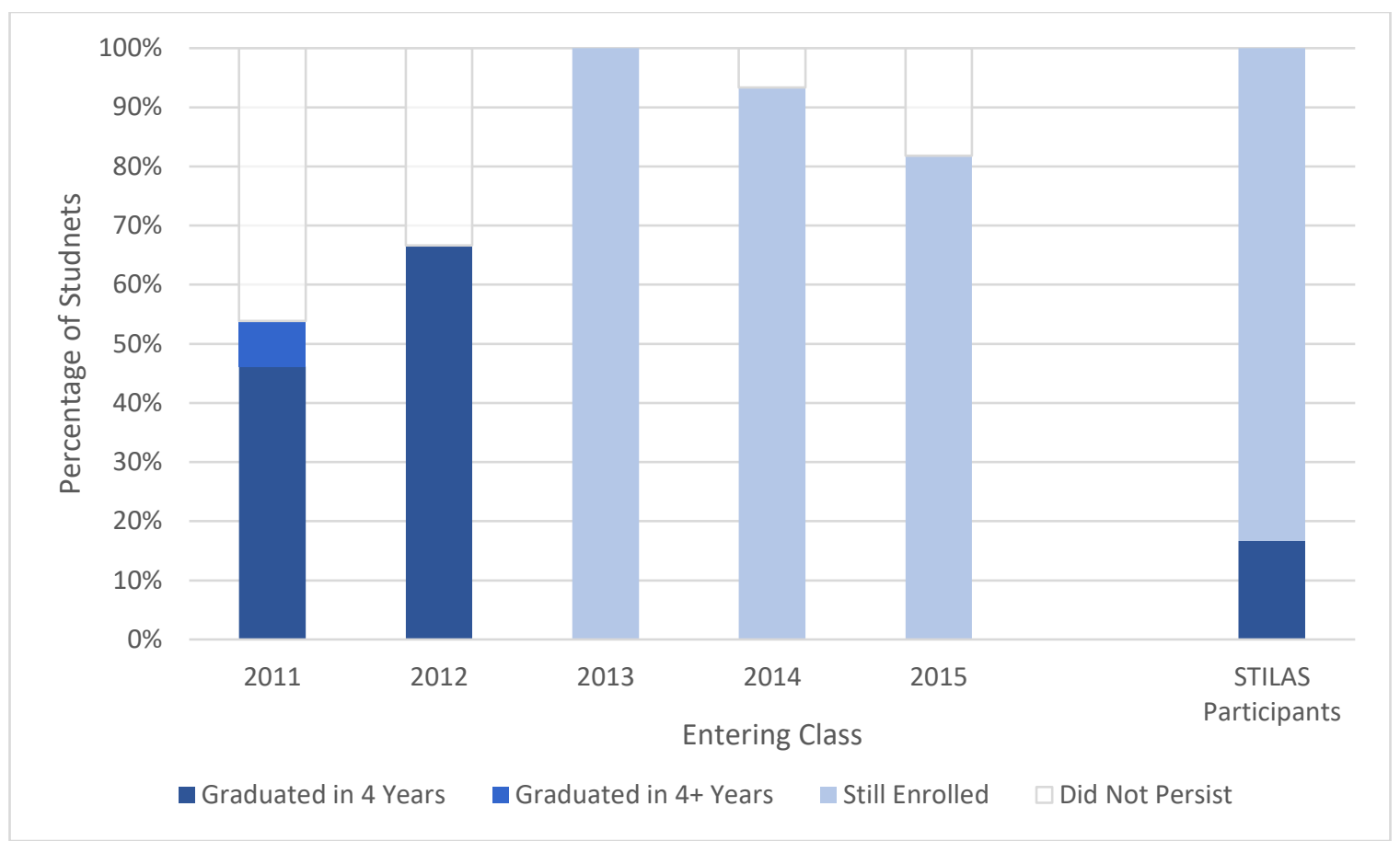

Figure 3: Persistence and graduation of women engineering students, by entering class.

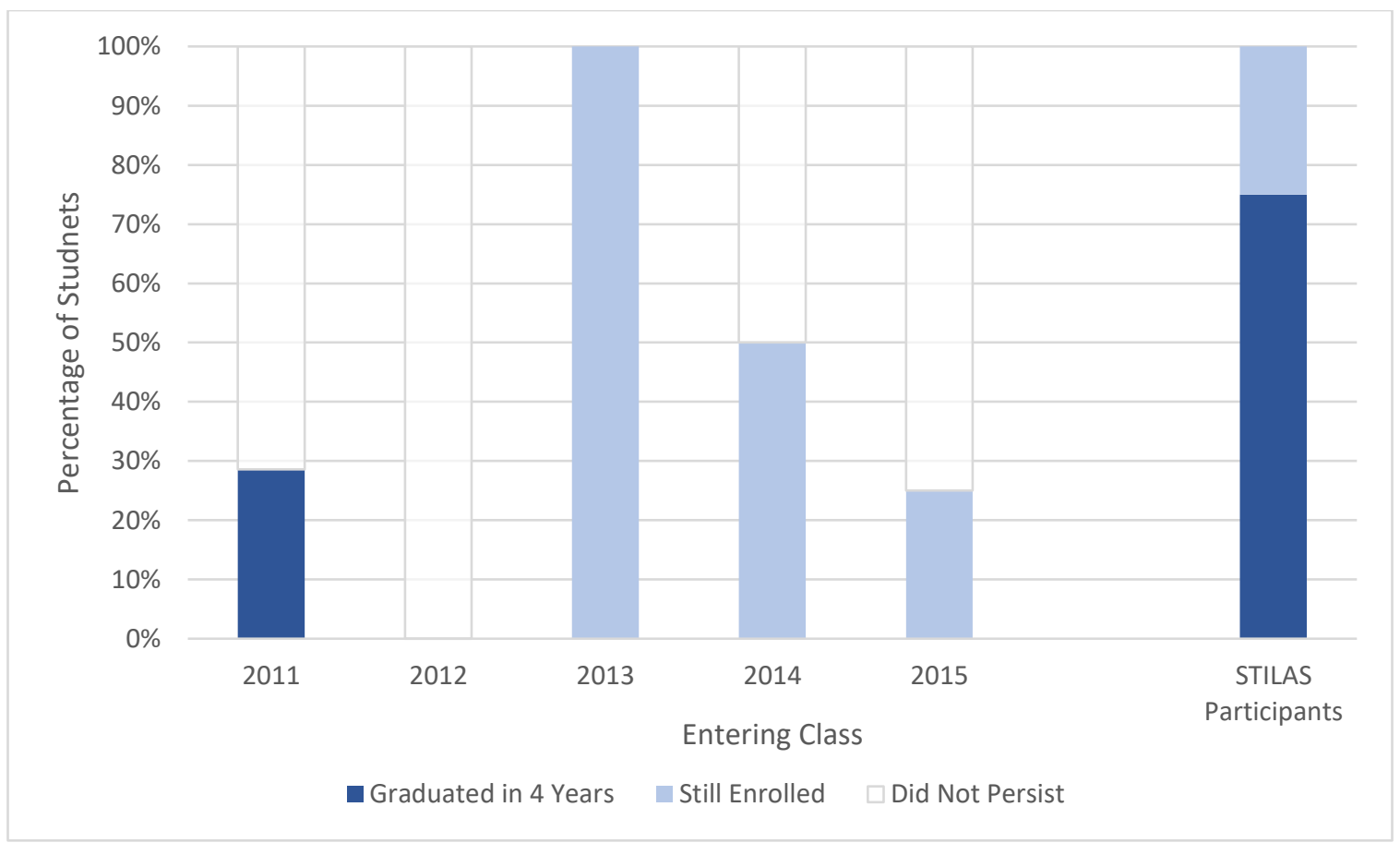

Figure 4: Persistence and graduation of underrepresented minority engineering students, by entering class. 


\section{Challenges and Lessons Learned}

The program's success has not come without challenges. These included:

- The late award date of the grant precluded active recruitment of the first group of students. Rather, they were selected from the limited number of eligible students on campus. Three in particular were academically marginal selections, and these students were not retained in STEM majors. Students who were actively recruited for the second and third years performed better, and students chosen to replace lost students performed the best of all, as they were chosen on the basis of their proven success at the university. Results could be improved significantly by structuring the grant funding to start a year or more before the first students matriculate, providing time to get the recruitment program up and running.

- Because of how underrepresentation in STEM fields is defined, the cohort included two distinct demographic categories: women engineers, who were all white, and underrepresented minorities, who were mostly male. We found that these two groups had unique needs and required different types of support.

- Integrating the STILAS students with the ILA program did not produce the expected synergy. Although STILAS and ILA students share the experience of being from an underrepresented population on campus, their academic experience is quite different (STEM vs. mostly non-STEM). The tutoring center, with its experience catering to STEM students, was better positioned to support the STILAS cohort. It also provided a point of commonality between the engineers and the biology students: both majors require math and science courses, and students in both majors often find these their most challenging courses.

- The financial eligibility requirement proved challenging to navigate. In some cases we could not offer students paid summer research positions because doing so would reduce their financial need to the point that it made them ineligible for the scholarship. We could not offer them unpaid summer internships because they could not afford on-campus summer housing, and we could not offer them partially paid internships without violating the university's minimum wage. As a result, some students worked menial summer jobs while living at home so as not to lose financial eligibility for the scholarship.

Another frustrating situation occurred when a student chose to move off-campus to find a quieter study environment. Because the private rental was cheaper than on-campus housing, it lowered his financial need and made him ineligible for the scholarship. We strongly wished to keep him in the program, and he wanted to stay as well, but felt he really needed to live off-campus. In the end he did move, lost the NSF portion of the scholarship, but continued to participate in cohort activities. We hope that the university and/or NSF can find ways to address these sorts of issues in future S-STEM grants.

- The five-year cycle of the S-STEM grants makes it difficult to maintain a steady recruitment program. Unless the host university is willing to cover the gaps, the five year grants allow for only two incoming classes to receive a full four-year scholarship. As a result the university must blitz for two to three years to recruit students, then stop recruitment for three years while the grant plays out, before applying for another S-STEM grant and then restarting the recruitment blitz. The on-again, off-again pattern makes it 
difficult to establish steady recruitment activities that might serve both the S-STEM cohort and the university at large. We hope NSF might consider means to structure the grants on a longer time scale, or allow for rolling renewals.

- Although the proposal envisioned a relatively steady cohort of students progressing together through the program, the cohort has experienced turnover as students lost academic or financial eligibility or transferred to other institutions. This impacted the cohesiveness of the cohort to some degree.

- Students found the number of activities excessive, as their schedules are already packed with academic, extracurricular, professional, social, and familial obligations. The proposal imagined a plethora of mentoring and events, but we pared these back a bit over the years. The students responded better to having a few "big-ticket" events than to a steady stream of small events.

\section{Conclusions}

Overall the STILAS program has been very successful, particularly for the engineering participants. While these were strong students to begin with, their performance has exceeded the levels typically seen for comparable students. The program has enabled them to obtain a highquality education that they could not otherwise afford. The students' success will be the nation's success, and we thank NSF for investing in their great future.

The results for the biology/marine biology students were not as good. These students were typically not as strong as the engineers coming in. Unfortunately we do not have extensive baseline data for the biology/marine biology programs, so we cannot readily benchmark the biology students' performance relative to comparable peers. We can only speculate as to possible causes. Without the option of selecting women (who are not underrepresented in the biological sciences), we had a smaller pool of prospective students to draw from. In addition, it may be that the engineering department is more supportive than the biology department, which has a higher level of research activity and hence less time for teaching.

Beyond the impact on the participants, the STILAS program has benefited the university and society at large. Although we cannot prove causation, the retention of underrepresented engineering students at Roger Williams University has dramatically increased during the grant period. Beyond our institution, the STILAS program has demonstrated the benefits of housing an S-STEM program within a campus tutoring center. In our annual reports and publications, including this one, we have highlighted opportunities for other universities to improve their STEM retention programs, and for NSF to improve the S-STEM program as a whole.

Limitations of the project include its modest scale. Obviously, a larger cohort would have a larger impact. In addition, the small scale of the university may limit the transferability of the STILAS program's methods to larger institutions. The RWU Engineering Department in particular is very close-knit and familial. With only eight full-time faculty members, most students have each professor several times and get to know them personally. Faculty are immediately aware of students' struggles both in and out of the classroom. Although we structured the STILAS program 
to have students meet frequently with their advisors, the reality is that they would have done so anyway. It is difficult for a student to fall through the cracks. Clearly such an environment supports the goals and methods of an S-STEM program. It is unclear how well the STILAS model would work in a less personal setting.

Future work focuses on improved recruitment. It proved harder to recruit underrepresented minorities than to keep them. Academically talented students have many options, some with more resources to offer. We plan to redouble our outreach to local high schools, and work to improve our bridge and transfer programs.

\section{Acknowledgments}

Funding for the STILAS program was provided by NSF under DUE-1154354. We would like to thank the S-STEM program officers and anonymous reviewers, as well as the original PIs, Professors Lonnie Guralnick and Linda Riley. Additional assistance was provided by members of the STILAS Steering Committee, including Karen Bilotti and Tracey McDonnell Wysor. Lastly, we thank our STILAS students for inspiring us every day.

\section{Bibliography}

[1] National Science Foundation. (2017). NSF Scholarships in Science, Technology, Engineering, and Mathematics Program (S-STEM). Retrieved from https://www.nsf.gov/funding/pgm summ.jsp?pims_id=5257\&org=DUE\&from=home.

[2] National Science Foundation. (2017). RWU STILAS-STEM Intercultural Leadership Ambassador Scholars in Biology, Marine Biology, and Engineering. Retrieved from https://www.nsf.gov/awardsearch/showAward?AWD_ID=1154354.

[3] Roger Williams University. (2017). Fast Facts. Retrieved from http://rwu.edu/about/who-we-are/fast-facts.

[4] National Center for Education Statistics. (2017). College Navigator: Roger Williams University. Retrieved from https://nces.ed.gov/collegenavigator/?q=Roger+Williams+University\&s=all\&id=217518. 